This item was submitted to Loughborough's Research Repository by the author.

Items in Figshare are protected by copyright, with all rights reserved, unless otherwise indicated.

\title{
Socio-emotional and operational demands on service employees
}

PLEASE CITE THE PUBLISHED VERSION

http://dx.doi.org/10.1016/j.jbusres.2014.04.022

\section{PUBLISHER}

(C) Elsevier Inc.

\section{VERSION}

AM (Accepted Manuscript)

\section{PUBLISHER STATEMENT}

This work is made available according to the conditions of the Creative Commons Attribution-NonCommercialNoDerivatives 4.0 International (CC BY-NC-ND 4.0) licence. Full details of this licence are available at: https://creativecommons.org/licenses/by-nc-nd/4.0/

\section{LICENCE}

CC BY-NC-ND 4.0

\section{REPOSITORY RECORD}

Lings, I., G Durden, Nick Lee, and John W. Cadogan. 2019. "Socio-emotional and Operational Demands on Service Employees”. figshare. https://hdl.handle.net/2134/17717. 
Socio-Emotional and Operational Demands on Front Line Service Employees: Implications for Burnout

Ian Lings

Geoffrey Durden

Nick Lee

John W. Cadogan,

Journal of Business Research, forthcoming. 


\section{Introduction}

The service-dominant logic (Vargo and Lusch, 2005) articulates the belief that interactions between the firm and its customers take place for the purpose of mutual value co-creation (Vargo and Lusch, 2005, 2008). Value co-creation often requires close interactions between front line employees and customers. These close interactions require that employees engage in task directed "operational" roles at the same time as fulfilling interpersonal "socioemotional” roles. Employees have finite resources (e.g. time, energy, knowledge, emotions) to dedicate to the service role. Conservation of resources (COR) theory (Hobfoll, 1988, 1989) predicts that if job demands exceed the limits of these available resources, employees will experience stress. This is often associated with employee burnout, which can compromise performance (Karatepe and Uludag, 2008).

Understanding the causes of employee burnout can provide benefits for employees, their employers and the national economy. The American Institute of Stress states that stress is an integral factor in up to $80 \%$ of work-related injuries and $40 \%$ of employee turnover (Atkinson, 2004). Furthermore, burnout costs organizations billions of dollars in disability claims, absenteeism and lost productivity (e.g. Schaubroeck, Jones, and Xie, 2001) and may cost up to 10\% of a country’s GNP (Ongori and Agolla, 2008).

Given the potential for severe detrimental consequences of burnout for employees, employers, and governments, and the dominance of service employment in many economies, understanding the simultaneous impact of operational- and socio-emotional demands on employees is a priority for services managers. Service providers must have a more complete understanding of the antecedents to stress and burnout if they are to develop better procedures to ameliorate the detrimental impact of excessive job demands on employee wellbeing, value co-creation and service performance. 
One service context in which high operational and socio-emotional demands are ubiquitous is healthcare. An abundance of research examines the antecedents of burnout in such settings. For example, the impact of role stressors on burnout in clinical settings is well established (see Lee, Lim, Yang and Lee 2011, for a meta-analysis). More currently, an historical focus on clinical workers is expanding to include non-clinical front line health service employees. For example, Ashill and Rod (2011) present empirical evidence that job demands made of non-clinical front line health service employees give rise to burnout symptoms in non-clinical health service encounters. Non-clinical health care workers, (especially allied health professionals such as physical therapists, psychologists, respiratory therapists, dietitians, podiatrists etc.) typically have high degrees of face-to-face interaction with patients. In such settings, the logic of value co-creation suggests that job demands include both operational and socio-emotional demands.

Building on earlier work by Rafaeli \& Sutton (1987), Zapf et al. (2001), Stordeur et al. (2007) and Ashill \& Rod (2011), this paper expands the conceptual domain of job demands to delineate operational demands and socio-emotional demands and to further differentiate between socio-emotional demands for dissonant and harmonious emotional displays. The study subsequently tests the impact of these demands on employee burnout symptoms in a high contact, non-clinical health care setting.

Hypotheses that posit the relationships between the various components of job demands (operational- and socio-emotional-), and burnout symptoms are presented. These are tested using data from a sample of a professional allied health association. The results suggest that health care managers must be cognizant of the dual demands made on their allied health care workers when they interact with patients and the consequences that these demands have for employee well-being. 


\section{Background}

Service roles, where the stakes for customer satisfaction and value creation are high, are inherently stressful. Service employees are required to simultaneously fulfill the operational demand to enact value-creating behaviors (serving customers), and fulfill the socio-emotional demands inherent in these behaviors, i.e. modify their behaviors in order to act in a way that is consistent with the position of their employer. Inherent in these requirements are the foundations for several managerial challenges. For a variety of reasons, service employees may not fully understand the task related behaviors that they are required to enact. Customer service behaviors may not be well understood by the firm, and so expectations of service staff behaviors may be unclear, giving rise to role ambiguity. Even if the employer is clear about the task behaviors that service personnel should enact, this may not be communicated to service staff transparently, again giving rise to role ambiguity, or, in the case where task behaviors are clearly communicated, but are too demanding on employees, role overload. Role conflict is also thought to be important in the co-creation process. Role conflict occurs when the firm and its customers may have different views of what constitutes value, and make conflicting demands on employees. Employees may feel conflict between fulfilling customer satisfying and employer satisfying behaviors (Chung and Schneider, 2002). While results remain inconclusive, work by Zapf et al. (2001) and Ashill and Rod (2011) reports significant relationships between operational role stressors and burnout symptoms in nonclinical health care workers.

Leaving aside issues of self-image and status within the customer and employer roles, it appears that employees may be required to modify their innate behavior to some extent in order to facilitate the service interaction. This dramaturgical perspective of service delivery is well established in the extant literature (for a comprehensive discussion of dramaturgy in service encounters, see for example Halliday, Davies, Ward, and Lim, 2008). From the 
perspective of the firm, such a point of view emphasizes the need for service employees to maintain an appropriately sociable demeanor, often requiring that they modify their behavior and act in a brand-appropriate manner (Jeanquart Miles and Mangold, 2004). The socioemotional demand to maintain a demeanor consistent with service norms may require service employees to suppress certain emotions that are seen as inappropriate to the service role (such as boredom, disliking or anger), whilst expressing others (such as excitement, friendliness and empathy), even if they do not genuinely feel these emotions. Expressing job demanded emotions to customers requires employees to expend energy to ensure that they display appropriate feelings, a process that is referred as emotional labor (Hochschild, 1983). Previous research provides conflicting results for the impact of emotional labor on burnout symptoms; sometimes regulating emotions is positively associated with burnout, sometimes negatively and sometimes it is not associated with burnout (Barsade, Brief, \& Spataro 2003). Despite ambivalent results from previous research the dominant paradigm in the filed is that emotional labor induces emotional dissonance (Grandey, 2000; Hochschild, 1983) and that sustained emotional dissonance leads to feelings of stress, frustration, or burnout/emotional exhaustion (Grandey, 2000; Hochschild, 1983; Judge, Woolf, and Hurst, 2009). With the exception of Rafaeli \& Sutton (1987), the majority of emotional labor research focuses on the negative consequences of emotional dissonance and largely ignores situations where employees appropriately express their genuine emotions, assuming that such genuine displays do not impact emotional exhaustion. In contrast Rafaeli \& Sutton (1987) highlight the positive outcomes of emotional harmony, which they define as the match between experienced and expressed emotions, and emotional norms. Emotional harmony would be achieved in the case when a service employee expresses genuine positive emotions in the service encounter and Rafaeli \& Sutton (1987) argue that it is associated with employee wellbeing. 
Concurrent socio-emotional and operational demands appear to be a common characteristic of the allied health professional's role, where value creation requires close interaction between the health professional and the patient. Research shows that both operational demands, in the form of role stress, and socio-emotional demands, in the form of emotional labor, independently give rise to employee burnout, and that the latter has a deleterious impact on employees' mental and physical health (e.g. Spector, Chen, and O’Connell, 2000). The majority of existing burnout research generally either focuses on the consequences of operational role demands, or socio-emotional role demands (see for example Ashill and Rod 2011; Karatepe and Uludag 2008). Studies focusing on either operational or socio-emotional demands neither reflect the complexity of service roles, nor capture the extent of the demands made of service employees. Consequently services researchers may underestimate the potential for burnout amongst service workers, especially those in high contact service situations. A few studies examine the simultaneous effect of job demands on burnout symptoms. Most notably, Zapf et al. (2001) examine the impact of a range of job stressors and emotion work on burnout across a range of services, and Stordeur, D'hoore and Vandenberghe (2001) examine the impact of psychological and role stressors on emotional exhaustion. Both of these studies focus on the negative consequences of emotional dissonance. However, in neither case is the potentially ameliorating impact of emotional harmony on burnout symptoms considered. This omission is important, since a situation where an employee expresses genuine emotions is clearly completely different from one in which an employee must suppress those emotions, and express 'false' emotions. Indeed, only the latter is likely to lead to burnout.

Zapf et al. (2001) and Stordeur et al. (2007) report that emotional labor does have an impact concurrent with role stressors on emotional exhaustion. Zapf et al. (2001) report that the additional impact of emotional labor on burnout, over and above task related job stressors, is 
rather small (3\%). Furthermore, Zapf et al. (2001) conclude that there may be conceptual overlap between emotional labor and job stressors, perhaps arising from the volume of work being undertaken. The Zapf et al. and Stordeur et al. studies represent an important first step in examining the concurrent impact of socio-emotional and task related stressors on burnout, however they both employ multiple regression analysis to examine the impacts. Standard regression analysis assumes that the constructs in the study are measured without error, and as such regression weights may be attenuated. This has the potential to give rise to misleading results; in particular, deflated regression results may lead to erroneous conclusions regarding the antecedents to burnout symptoms and an underestimation of their effect on burnout. Structural equation modeling (SEM) with latent variables has advantages over standard multiple regression techniques in situations where measured variables are subject to measurement error. When modeling latent variables, SEM accounts for the measurement error in indicator measures and allows latent variables to be modeled without the implicit assumption of zero error, as is the case implicit in standard regression techniques. SEM also allows for more complex relationships, such as those between the dimensions of burnout and their antecedents to be simultaneously estimated, providing a more representative description of the relationships between study constructs.

\section{Role demands and burnout.}

Conservation of resources (COR) theory (Hobfoll, 1988, 1989) suggests that employees who experience pressure to enact multiple roles that exceed the limits of their available resources will experience stress and symptoms of ill health (Kahn, Wolfe, Quinn and Rosenthal, 1964). According to COR, individuals accumulate personal resources such as motivation and energy. Stressful events consume these resources and "people strive to obtain, retain, protect, and foster valued resources and minimize any threats to resource loss” (Brotheridge \& Lee, 
2002: 58). In the context of this research, resource threats include the effort required to fulfill operational and socio-emotional role demands, which will impact energy and motivation resources amongst others. In order to best conserve their resources, employees make decisions about how much effort to invest in fulfilling the service role, based on their expectations of the outcomes of the role and the anticipated return on the investment of resources. When the net outcomes of the service role are positive, people experience a surplus in their "resources" and are motivated to take part in similar transactions in the future. When resources cannot be regained, people experience stress and burnout. The conservation of resources theory is not new to the research field, and is used to study emotional labor and burnout (Brotheridge \& Lee, (2002)

In the context of operational demands; role stressors (resource demands) comprise three separate but related constructs; role overload, role ambiguity and role conflict (Kahn, 1980; Schaubroeck Cotton and Jennings, 1989; Kelloway and Barling, 1990; Peiro et al., 2001; Peterson, Smith, Akande, Ayestaran, et al., 1995). Role overload exists when role expectations are greater than the individual's abilities and motivation to perform a task (Schaubroeck, et al., 1989; Spector and Jex, 1998; Conley and Woosley, 2000). Role ambiguity arises when individuals do not have clear authority or knowledge about how to perform the assigned jobs (Rizzo, House and Lirtzman, 1970; Ivancevich and Matteson, 1982; Ashforth and Lee, 1990; Singh, Goolsby, and Rhoads, 1994). Role conflict refers to incompatibility of expectations and demands associated with the role (Rizzo et al., 1970; Ivancevich and Matteson, 1982; Ashforth and Lee, 1990).

In the context of the socio-emotional role, resource demands consist of the effort required to modify one's displays of emotions to conform with service norms 


\section{Conceptual framework}

\subsection{Burnout}

Burnout is historically conceptualized as containing three distinct but related components: emotional exhaustion, depersonalization, and reduced personal accomplishment. Emotional exhaustion reflects a sense of energy depletion due to excessive psychological demands, depersonalization is reflected in the tendency to treat other people as things and reduced personal accomplishment is reflected in declining feelings of achievement in work (Maslach and Jackson, 1981).

Researchers are yet to reach consensus on how the three components underpinning burnout might be related to each other. For example, Golembiewski and Munzenrider (1989) propose a process model in which depersonalization develops as a coping strategy in stressful situations, and this in turn leads to diminished personal accomplishment, which in turn leads emotional exhaustion. Van Dierendonck et al. (2001) suggest that lack of personal accomplishment influences depersonalization and depersonalization in turn influences exhaustion. Taris et al. (2005) suggests a model where exhaustion causes depersonalization over time, and the latter drives high exhaustion and lower levels of personal accomplishment. Yet others characterize burnout either in terms of emotional exhaustion only, arguing that emotional exhaustion is the dominant aspect of burnout (e.g. Stordeur et al., 2001; Kristensen, Borritz, Villadsen, and Christensen, 2005), or as a two dimensional construct comprising emotional exhaustion and depersonalization, arguing that personal accomplishment is largely independent of these other dimensions of burnout (e.g. Hakanen et al., 2008).

In this study, we subscribe to Leiter and Maslach (1988) and Kristensen et al.'s (2005) broad notion that emotional exhaustion plays a dominant role in shaping other burnout outcomes, and follow Leiter's (1993) argument that emotional exhaustion is a source of both 9 
depersonalization and of diminished personal accomplishment, with the latter two constructs being separate outcomes of emotional exhaustion. Indeed, many studies report emotional exhaustion to be the first sign of burnout with depersonalization and diminished personal accomplishment occurring later. Accordingly, the components of burnout are causally related with emotional exhaustion developing from excessive work demands and depersonalization and reduced personal accomplishment emerging as consequences of emotional exhaustion. As such we hypothesize that

H1: There is a positive relationship between emotional exhaustion and depersonalization

H2: There is a negative relationship between emotional exhaustion and personal accomplishment

\subsection{Operational demands and emotional exhaustion}

The relationship between operational demands, in the form of role stressors, and burnout symptoms is extensively examined in the literature. Role stressors are generally considered to be 'hindrance' stressors, which are appraised by individuals as constraining their potential for personal development and workplace accomplishment (Podsakoff et al., 2007). Within this context, four role stressors are generally considered to be especially relevant in frontline roles. Of the four, role conflict, role ambiguity, and role overload receive significant attention within frontline service settings as influences on emotional exhaustion, and we consider these three to be of particular importance. While a fourth, interpersonal conflict, is also investigated in the literature (e.g. Dormann and Zapf, 2004), we consider this concept to be quite unrelated conceptually. In fact, it seems conceptually more intuitive to consider interpersonal conflict as just one of the many characteristics of the frontline role that may or may not occur, and that may have some input into the role stress evaluation process of an individual. In this sense then, role conflict, role overload, and role ambiguity are considered "task related hindrance job demand stressors” (Ashill and Rod, 2001: p. 1123) 
Therefore, focusing on the three task-related role stressors of conflict, ambiguity, and overload, Lee and Ashforth's (1996) meta-analysis finds that role conflict contributes to emotional exhaustion but not to role ambiguity. Although Lee and Ashforth (1996) do not capture role overload directly, they do report a significant meta-correlation between the conceptually similar 'workload' construct and emotional exhaustion. In fact, it is rare that a study is able to find significant results between all three of the task-related role stressors under investigation here, with role conflict seeming to be the most consistent contributor to emotional exhaustion (see for example Sethi, Barrier and King, 1999; Fogarty, Singh, Rhoads, and Moore; 2000; Peiro et al. (2001; Posig and Kickul 2003; Bhanugopan and Fish, 2006; Zapf et al. ( 2007). In contrast, Stordeur et al. (2001) report that role conflict is not related to emotional exhaustion when modeled simultaneously with socio-emotional demands.

When specific investigations are made in settings similar to that of the present study, both Lee, Song, Cho, Za, and Daly (2003), and Ashill and Rod (2011) show that both role conflict and role overload lead to emotional exhaustion, although neither study reports a significant effect of role ambiguity on emotional exhaustion. Wu, Zhu, Wang, Wang, and Lan (2007) however do find a significant effect of both role overload and role ambiguity on emotional exhaustion.

\subsubsection{Role conflict and emotional exhaustion}

In the allied health context, role conflict typically arises in one of two ways. First, patients, or their relatives, may make demands of the service employee that conflict with the organization's position (such as asking for/needing additional services that have not been paid for) and the employee is asked to break, or bend, the rules in order to help the patient. Second, employees may perceive conflicting instructions for their role (e.g. they might 
perceive that operational targets for volume of work to be completed conflict with quality targets, for individual attention, or financial targets might be perceived to conflict with care giving targets). In such situations, employees need to resolve the conflict in order to complete their operational tasks and in so doing, they have to choose one of the conflicting targets to prioritize over the other. In both instances the employee will experience some cognitive dissonance. As they are conflicted between two valid demands, resolving this dissonance is associated with emotional effort and consequently emotional exhaustion.

Accordingly, we hypothesize that:

H3: There is a positive relationship between perceptions of role conflict and emotional exhaustion.

\subsubsection{Role ambiguity and emotional exhaustion}

Role ambiguity also has the potential to impact emotional exhaustion. When faced with unclear expectations and objectives in their role, employees are likely to feel that they cannot accomplish what is expected of them or meet their goals (as they do not know what they are). In the context of allied health professionals, potential role ambiguity can occur when the care giving role is inadequately defined. This may be the case for allied health professionals who find themselves required to perform multiple operational tasks when their specific role is less well defined or understood than, for example, clinical health care workers.

Accordingly we propose that:

H4: There is a positive relationship between perceptions of role ambiguity and emotional exhaustion.

\subsubsection{Role overload and emotional exhaustion}

The impact of role overload on emotional exhaustion is also established in the literature (See for example Ashill and Rod, 2011; Bhanugopan and Fish, 2006). Excessive operational 
demands or responsibilities require a level of effort that will eventually deplete the resources of the employee, giving rise to emotional exhaustion. In the allied health care context, role overload has the potential to be particularly prevalent as health budgets are archetypically tight, and clinical care typically takes funding precedence over allied health care. Consequently we hypothesize:

H5: There is a positive relationship between perceptions of role overload and emotional exhaustion.

\subsection{Socio-emotional demands and emotional exhaustion}

Notwithstanding operational demands, socio-emotional demands are also made of service employees; they are required to modify the emotions that they display in social interactions with customers. Satisfying these socio-emotional demands requires emotional labor (Ashforth and Humphrey, 1993). Emotional labor involves modifying emotional displays so that they are congruent with the service norms required by the firm. In particular, genuinely-felt emotions may need to be suppressed in favor of the overt display of other non-geniune emotions, depending on their appropriateness to the service encounter. While there is disagreement in the empirical literature, research generally suggests that dissonance between felt emotions and those expressed to adhere to service norms may have a detrimental effect on employees (Jenkins and Maslach, 1994).

Typically, service encounters require the expression of positive emotions, irrespective of whether they are genuine or not, and the suppression of negative emotions. For instance, genuine negative emotions, such as frustration or dislike, which are not appropriate in the service interaction, need to be suppressed. Conversely, if the service employee is not feeling positively inclined towards the customer, positive emotional displays, such as friendliness or enthusiasm, need to be contrived. Expressing contrived emotions, such as pleasure, liking and 
enthusiasm, is a form of surface acting and requires emotional effort, and as such, constitutes emotional labor.

Grandey, Fisk, and Steiner (2005, p. 894) term the process of modifying one’s expression of genuinely-felt emotions response-focused emotional regulation, and argue that it is "particularly critical in understanding” the stress-related responses of frontline workers, in particular because the regulation of expressed emotions is strongly linked to stress outcomes (e.g. Grandey, 2003), as well as draining cognitive and motivational resources, and causing decrements in task performance. Of particular relevance herein is that research finds that response focused emotional regulation increases emotional exhaustion (e.g. Grandey 2000). However, while the negative effects of suppressing genuine emotions are receiving significant attention, there is much less work examining the potential positive effects of expressing genuinely-felt emotions. Such work is important though, since the consequences of the expression of genuine emotions are likely to be strongly dependent on the valence of the genuinely-felt emotion, because of the norms of the frontline service context. In particular, in some cases, there should be a positive impact on employee well-being when there is congruence between felt emotions and those emotions expressed to adhere to service norms (emotional harmony) (Rafaeli \& Sutton, 1987). On the other hand, in the service context, expressing genuine negative emotions may indicate a negative interaction between service worker and client. The latter is incongruent with service norms, and should lead to a negative outcome.

For example, if the service employee is feeling genuinely positive towards the customer, expressing those genuine positive emotions would be intrinsically rewarding and may represent a form of emotional release, allowing the service employee to relax into their role, replenish emotional resources and reduce their perception of the effort required to serve customers. As Brotheridge \& Lee (2002) suggest, when the net outcomes of the service role 
are positive, people experience a surplus in their resources and so the experience of stress and burnout will be reduced.

However, if the employee is feeling genuinely negative towards the customer, and expresses these genuine negative emotions in the service encounter, they are breaching the norms of the service encounter. This constitutes a form of emotional dissonance, as it is incongruent with service norms, and consumes emotional resources, increasing burnout symptoms. Notwithstanding some specific service interactions, such as teaching, policing and debtcollecting, where negative interactions might need to be contrived, typically market encounters do not call for service employees to either affect negative emotions or suppress positive emotions in a service interaction. Both forms of acting would normally be considered counter to the service logic.

\subsubsection{Expressing genuine positive emotions and emotional exhaustion}

Given the imperative to provide high quality services, service employees are cognizant of the need to interact appropriately with customers (i.e. express positive emotions and suppress negative ones). Employees who are genuinely experiencing positive emotions toward customers are not required to expend cognitive effort to express these genuine positive emotions in the service interaction. In line with Rafaeli \& Sutton, (1987) we argue that this emotional harmony allows the employee to recoup emotional resources and alleviates employees’ feelings of emotional exhaustion.

Thus, consistent with previous work, and as explained above, we propose that:

H6: There is a negative relationship between expressions of genuine positive emotions in the service encounter and emotional exhaustion. 


\subsubsection{Expressing genuine negative emotions and emotional exhaustion}

The expression of genuine negative emotions indicates a negative interaction, but does not require the employee to modify their emotional display. If the employee is feeling genuinely negative towards the customer, then through frustration, or lack of attention, the employee may express this negative emotion. This emotional release would constitute a reduction in the effort required to manage emotion and so should reduce emotional exhaustion. However, most employees are cognizant of the need to enact socially appropriate behaviors, and so, arguably, expressing negative emotions contradicts emotional norms in the service coproduction context. Consequently, we argue that expressing genuine negative emotions is a form of emotional dissonance and will be associated with increased emotional exhaustion.

H7: There is a positive relationship between expressions of genuine negative emotions in the service encounter and emotional exhaustion.

\subsubsection{Expressing contrived positive emotions and emotional exhaustion}

The need to express contrived positive emotions suggests a negative or, at best, a neutral interaction, and requires the employee to modify his/her emotional display to conform to service norms. This emotional management constitutes a form of emotional dissonance and requires effort, draws on employees’ emotional resources, and so increases perceptions of emotional exhaustion.

We therefore suggest that:

H8: There is a positive relationship between expressions of contrived positive emotions in the service encounter and emotional exhaustion. 


\subsubsection{Suppressing genuine negative emotions and emotional exhaustion}

Suppression of genuine negative emotions in the service interaction also indicates a negative interaction. Successfully suppressing negative emotions to conform to service norms requires effort. Drawing on emotional resources to do so increase employees' perceptions of emotional exhaustion.

Accordingly, we propose that:

H9: There is a positive relationship between suppression of genuine negative emotions in the service encounter and emotional exhaustion.

Figure 1 shows our operational model. Following Maslach, Jackson, and Leiter (1996), burnout is conceptualized as a set of three components, emotional exhaustion depersonalization, and (reduced) personal accomplishment. Emotional exhaustion is predicted by high socio-emotional demands associated with service interactions, where socioemotional demands are conceptualized as the extent to which service operatives are required to (a) display emotions that are socially appropriate to their role, and (b) suppress emotions that are seen as socially inappropriate. Emotional exhaustion is also believed to result from role ambiguity, conflict and overload, deriving from operational demands of the service role. Despite the significant aforementioned consequences of burnout, few studies examine the concurrent impact of role stress and emotional labor on burnout, and those that do focus exclusively on emotional dissonance as a feature of emotional labor, and do not take into consideration the potentially ameliorating impact of emotional harmony on burnout symptoms. Furthermore, research examining the concurrent impact of task- and socioemotional demands on burnout (e.g Stordeur at al 2001 and Zapf et al., 2001) models the relationships using regression techniques. This may give rise to under-estimations of the relationships between the constructs (Tremblay \& Gardner 1996). 


\section{Figure 1 Operational model}

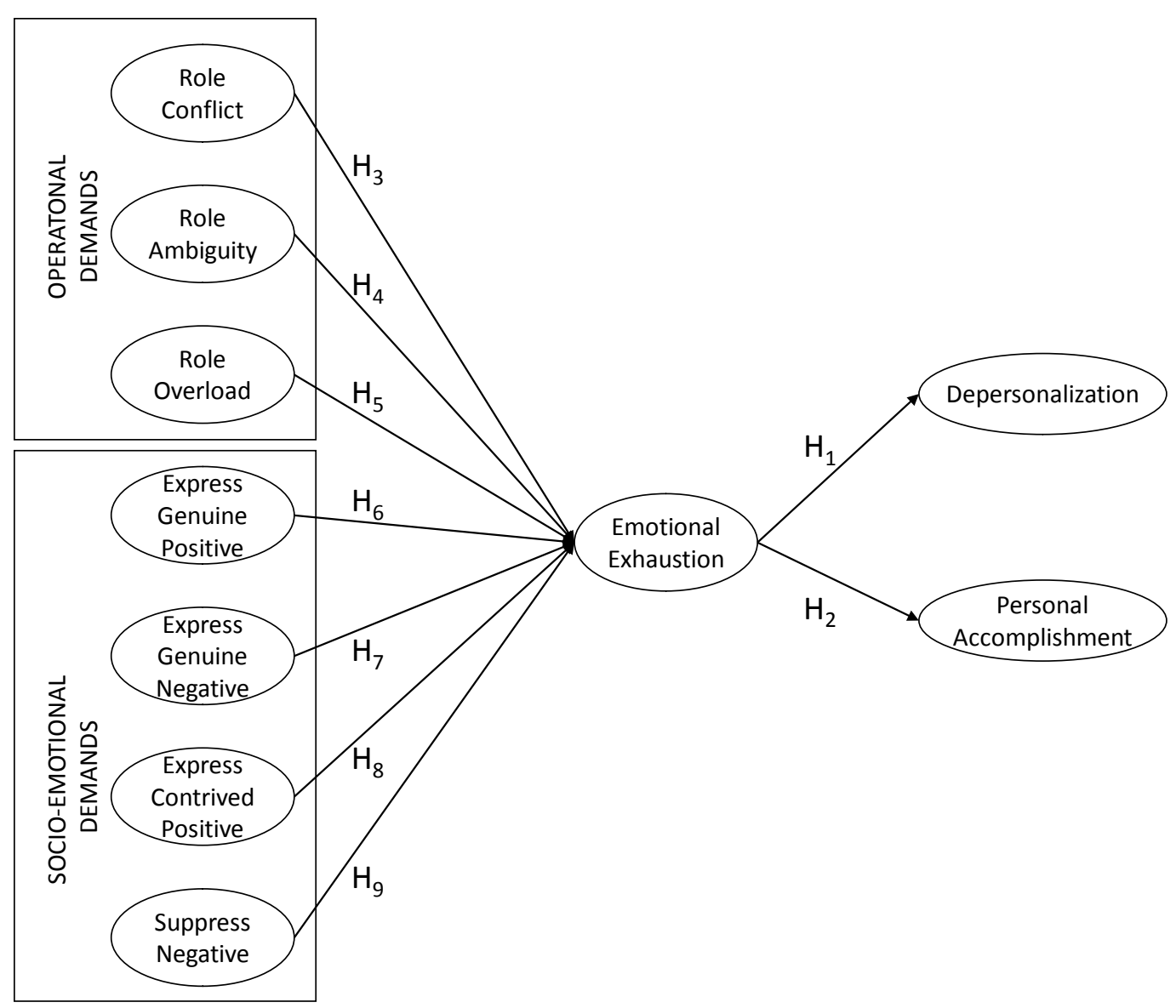

\section{Method}

In order to test the relationships between the constructs in our study, we collected data from front line service employees working in jobs with high levels of operational and socioemotional demands. We selected the Diversional Therapy Association of New South Wales, Australia as an appropriate context. Diversional therapy (which is sometimes called recreational therapy in the UK and USA) is an allied health service in which customers are often very physically and emotionally dependent on the actions of service employees, and in which emotional displays by those employees are particularly important. Diversional 
therapists work with customers to achieve positive health outcomes by incorporating leisure programs into their lifestyles. In line with other health contexts, diversional therapists also find that they have many and varied operational demands on their time and often experience role stress derived from operational demands. Burnout is also reported to be high in health care occupations (Tourigny, Baba, and Wang, 2010). This makes the diversional therapy context a particularly useful one in which to test these effects.

Data were collected by means of a self administered paper and pencil questionnaire. A survey pack containing the questionnaire, a letter of introduction and a pre-paid reply envelope was mailed to a census of the Diversional Therapy Association of NSW membership ( $n=520)$. A total of 129 complete responses (25\%), representing membership at all levels of the profession, were received. Respondents were overwhelmingly female (94 per cent), which is representative of the gender split in the profession.

\subsection{Measures}

All constructs were measured using commonly employed scales from published literature. The most well studied operationalization of burnout is the Maslach burnout inventory (Maslach and Jackson, 1981; Maslach, Jackson, and Leiter, 1996), which is the standard tool for measuring burnout. Burnout symptoms were measured using a modification of Maslach and Jackson’s (1981) burnout inventory (as cited in Kanste, Miettunen, and Kyngäs, 2006). Modifications of emotional displays were measured using elements of the emotional labor scale developed by Glomb and Tews (2004). Role stressors were measured using scales reported by Chen, Gully and Eden (2001). See Appendix 1 for a full list of these items.

\subsection{Measurement model tests}

Several approaches were engaged to establish the validity of the scales used in this study. In particular, it was important to establish the convergent validity of the scale items and the ability of these items to discriminate between the constructs of interest in this study. Tests to 
establish convergent and discriminant validity were consequently undertaken. These are presented next, along with further evidence to support the validity of the scales used.

Fornell and Larcker (1981) suggest that average variance extracted (AVE) is an appropriate, and stringent, test of the internal stability of a scale and the convergent validity of its items. Anderson and Gerbing (1988) offer an alternative heuristic: that significant t-values for the item loadings onto the construct of interest support the convergent validity of scale items.

Both assessments of convergent validity were undertaken. All items were found to load significantly onto the constructs that they were used to measure ( $\mathrm{t}$ value for all items $>5.5$ ). All scales also met the more stringent assessment recommended by Fornell and Larcker (1981) as the AVE for all scales exceeded the recommended minimum of $50 \%$ (See Appendix 2).

Evidence of discriminant validity is provided if the AVE of a construct is greater than the construct's shared variance with every other construct (i.e. AVE $>$ the square of the interfactor correlations between any two constructs) (Fornell and Larcker, 1981). In support of discriminant validity, analysis of the data (see Appendix 2) indicates that all AVE values exceed the squared correlations of their corresponding constructs. Establishing the discriminant validity of the measures in this study addresses one of the concerns raised by Zapf et al. (2001) regarding potential overlap between the role and socio-emotional demands made of service workers. Zapf et al. suggest that correlations between their measures of emotional labor and task stressors may be the result of overlap between the variables. While the results of our discriminant validity tests do not unequivocally rule out such overlap they do go some way to demonstrating that the measures of task and socio-emotional demands used in our study do differentiate between these constructs. 


\subsection{Composite reliability}

Having established that each of the scales measuring various constructs of interest do indeed discriminate between these constructs, the next stage in the analysis was to examine composite reliabilities of each of the scales (Gerbing and Anderson, 1988; Hair, Anderson, Tatham and Black, 1998, p. 611). These all exceed the recommended standards of Bagozzi, Yi and Phillips (1991) and Hair et al. (1998), providing evidence of the internal consistency of the construct indicators (see Appendix 2).

\subsection{Method biases}

The final empirical assessment of the scales was to investigate the presence of systematic measurement errors (bias). The potential for acquiescence bias was minimized by including both positively and negatively worded questions as recommended by Baumgartner and Steenkamp (2001). A further post-hoc test for common method bias, Harman's (1967) onefactor test, was performed. All of the self-report items were entered into a principal components factor analysis with varimax rotation. According to this technique, if a singlefactor emerges from the factor analysis or one-factor accounts for more than $50 \%$ of the variance in the variables, common method variance is present (Mattila and Enz, 2002). Our analysis revealed a thirteen-factor structure with no general factor present (the first factor accounted for $22 \%$ of the variance). Although this test does not rule out the presence of common method bias, combined with the measures taken in the questionnaire design to minimize acquiescence bias, it does provide support for the absence of such a general bias in the findings (Mattila and Enz, 2002).

\subsection{Test of the conceptual model}

Having established that the measures used in this study display adequate psychometric properties, the next stage in the research was to test the effects in the hypothesized conceptual 
model presented in Figure 1. The data were analyzed using structural equation modeling, employing LISREL 8.8 (Jöreskog and Sörbom, 2007).

\section{Results}

Table 1 Standardized parameter estimates for the structural model

\begin{tabular}{|c|c|c|c|}
\hline & Hypotheses & Path estimate & t-value \\
\hline $\mathrm{H} 1$ & Emotional Exhaustion -> (+) Depersonalization & .50 & $3.82 *$ \\
\hline $\mathrm{H} 2$ & Emotional Exhaustion -> (-) Personal Accomplishment & -.21 & $-1.88 *$ \\
\hline H3 & Role Conflict -> (+) Emotional Exhaustion & .42 & $1.86^{*}$ \\
\hline $\mathrm{H} 4$ & Role Ambiguity -> (+) Emotional Exhaustion & -.04 & -0.46 \\
\hline H5 & Role Overload -> (+) Emotional Exhaustion & .65 & $3.60 *$ \\
\hline H6 & Expressing genuine positive emotions -> (-) Emotional Exhaustion & -.41 & $-3.74 *$ \\
\hline H7 & Expressing genuine negative emotions -> (+) Emotional Exhaustion & .25 & $1.89 *$ \\
\hline H9 & $\begin{array}{l}\text { Expressing contrived positive emotions-> (+) Emotional Exhaustion } \\
\text { Suppressing negative emotions-> }(+) \text { Emotional Exhaustion }\end{array}$ & .28 & $\begin{array}{l}2.41^{*} \\
0.78\end{array}$ \\
\hline
\end{tabular}

The results show that the hypothesized relationships between the burnout symptoms are supported, with emotional exhaustion significantly predicting a substantial degree (25\%) of depersonalization (H1) and a relatively minor degree (5\%) of personal accomplishment (H2). As can be seen in Table 1, the model also reveals partial support for the view that operational demands lead to emotional exhaustion. Role conflict (H3: $\beta=0.42, \mathrm{p}<0.05_{(1 \text { tailed) }}$ ) and role overload (H5: $\beta=0.65, \mathrm{p}<0.05_{(1 \text { tailed) }}$ ) both significantly increase emotional exhaustion; role ambiguity (H4: $\beta=-0.04, \mathrm{p}>0.05_{(1 \text { tailed) }}$ ), on the other hand, does not.

The data also provide partial support for the thesis that socio-emotional demands impact burnout. Specifically, we find that expressing genuine positive emotions ameliorates 
emotional exhaustion (H6: $\beta=-0.41, \mathrm{p}<0.05_{(1 \text { tailed) }}$ ) and does not undermine employee wellbeing. In contrast, expressing genuine negative emotions is emotionally taxing and leads to emotional exhaustion (H7: $\beta=0.25, \mathrm{p}<0.05_{(1 \text { tailed) }}$ ), while contriving positive emotions (surface acting) is confirmed as a form of emotionally demanding work (H8: $\beta=0.28$, $\left.\mathrm{p}<0.05_{(1 \text { tailed) }}\right)$ and has the potential to damage the well-being of service employees. However, suppressing negative emotions does not appear to constitute emotional labor and has no

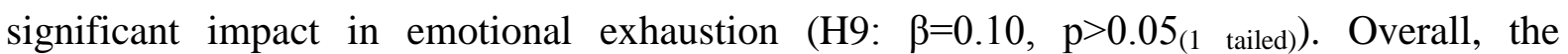
operational and socio-emotional demands predict over half of the emotional exhaustion that employee’s experience. $^{1}$

\section{Discussion}

The findings of our study suggest that both socio-emotional demands and operational demands are powerful determinants of workplace stress. First we address the relationship been operational stressors and burnout; this is followed by an examination of the results pertaining to socio-emotional demands and burnout; and finally, we compare our nomological framework with previous work in the area and explore its merits and limitations.

\subsection{Operational demands}

Our findings concerning the various operational demand constructs are broadly consistent published work in this area (see for example Schaufeli and Bakker 2004; Stordeur et al., 2007; and Zapf et al., 2001) and conform to the predictions of the COR model. However, our results diverge from those of published studies in several significant areas.

\subsubsection{Role overload}

In this study, the most substantial operational demand is found to be role overload. This is consistent with the COR theory predictions and conforms to much prior work in this area. 
Researchers examining the concurrent impact of socio- emotional and operational demands on employee burnout so not specifically examined role overload, so the models are not directly comparable. However, Zapf et al. (2001) report a significant correlation between time pressure and emotional exhaustion, and Stordeur et al. (2001) report a significant relationship between workload and emotional exhaustion. In all three studies (including ours) overload (time pressure, work load) is found to be the most substantial predictor of emotional exhaustion. Stordeur et al. (2001) and Zapf et al. (2001) use standard linear regression analysis to model the simultaneous impact of socio-emotional and operational demands on emotional exhaustion. As already discussed, regression analysis may suffer from attenuation bias, in that the estimated regression weights may be smaller than the true effect sizes. SEM controls for measurement error and reduces attenuation bias (Tremblay \& Gardner 1996). Consistent with the presence of attenuation bias in earlier work, the relationship between overload and emotional exhaustion is substantially stronger in our model $[\beta=0.65$ in our study versus. 0.22 (Zapf et al) and 0.28 (Stordeur et al)].

\subsubsection{Role Conflict}

Zapf et al. (2001) do not examine role conflict, but do examine organizational problems, which include "using tricks to get the job done” which is conceptually similar to conflict. They report that organizational problems are a significant predictor of emotional exhaustion ( $\beta=0.19)$. In contrast, Stordeur et al. (2001) measure role conflict directly and report that it is not a significant determinant of emotional exhaustion. We find that role conflict is both a significant and substantive $(\beta=0.42)$ determinant of emotional exhaustion, supporting the findings of Zapf et al. (2001). Again, our findings are consistent with the presence of attenuation bias in both the Zapf et al. and Stordeur et al. studies, and it is feasible that the non-significant results of Stordeur et al. (2001) result from this bias. Similarly, the weak 
association between organizational problems and emotional exhaustion in the Zapf et al. study may also be the result of attenuation bias.

\subsubsection{Role Ambiguity}

Our findings also contrast with those of Stordeur et al. (2001) in that our results suggest that role ambiguity is not a significant determinant of emotional exhaustion $(\beta=-0.04)$. Stordeur et al. report that role ambiguity is a significant, but weak $(\beta=0.17)$ predictor of emotional exhaustion. A plausible explanation for the differences in these findings is offered by Meyerson (1994). Meyerson examine role ambiguity and burnout in a sample of social workers and find that social workers who conform to a medical ideology experience ambiguity as negative and disabling. In contrast, social workers conforming to a social work ideology see ambiguity as normal and often enabling. Diversional therapists share many similarities with social work: both are allied health occupations, and both are not primarily focused on a medical model of treatment. In the medical model of treatment death is viewed as a negative outcome and is seen as failure. However, the majority of diversional therapists work with terminally ill patients and strive to achieve a 'good' death for these patients, recognizing that extending life is not always achievable, or desirable. It may be that, in rejecting the medical model, diversional therapists embrace ambiguity more and see it as a normal part of work/life. As such, ambiguity would be expected to have less impact on emotional exhaustion in diversional therapists than in clinical staff, who adhere more strongly to the medical model and consider ambiguity as negative and disabling.

\subsection{Socio-emotional demands}

Our results suggest that the different socio-emotional demand constructs act to increase burnout symptoms when displayed emotions are incongruent with felt emotions or with 
service norms. Where displayed emotions, felt emotions and service norms are in harmony, burnout symptoms are reduced. This is a unique contribution of the present study.

\subsubsection{Emotional Harmony}

The most substantial influence on burnout is the ameliorating impact of expressing genuine positive emotions on emotional exhaustion $(\beta=-0.41)$. Expressing genuine positive emotions is congruent with service norms and suggestive of a positive service encounter. This ameliorating effect of emotional harmony is in accordance with the proposition of Rafaeli \& Sutton (1987) who suggest that emotional harmony should have a positive impact on employee wellbeing. The finding is also consistent with the predictions of COR theory. Brotheridge \& Lee (2002) suggest that if employees experience emotional harmony and are engaged in a fruitful positive service encounter they experience a surplus in their "resources" and reduce emotional exhaustion. Excluding the current study, the existing studies that examine the concurrent impact of socio- emotional and operational demands on employee burnout fail to examine the ameliorating impact of emotional harmony on burnout symptoms, and our finding is an important advancement of previous models. More specifically, without an understanding that sometimes emotional displays are genuine, research fails to accurately model the phenomena of interest. Particularly, missing out an important predictor of our focal consequence (burnout) may lead to misrepresentation of the true effects of predictors - and indeed, our results suggest that existing work may suffer from such biases. Modeling the influence of emotional harmony along with emotional labor is therefore desirable in trying to explain burnout in service employees.

\subsubsection{Emotional Dissonance}

In line with previous studies we find that emotional dissonance significantly predicts emotional exhaustion (see for example Grandey, 2000; Hochschild, 1983; Judge, Woolf, and 26 
Hurst, 2009). Expressing contrived positive emotions increases the level of emotional exhaustion that service employees feel (H8). This possibly reflects the burden of maintaining a cheerful and helpful demeanor when the service provider does not feel this way. Expressing genuine negative emotions also increases emotional exhaustion (H7). Both forms of emotional expression constitute emotional dissonance, the first because the felt emotions are incongruent with those expressed to conform to service norms, the second because those expressed are incongruent with service norms.

The socio-emotional demands on these service employees are not characterized by the need to express contrived negative emotions, which accords with the proposition that contrived negative emotions are unlikely to figure in the emotional repertoire of health care professionals.

\subsection{Summary}

Taken together, we argue that the multiple socio-emotional and operational demands conceptualized herein reflect the generalizable operating characteristics of professional service organizations, namely, high levels of service employee-client contact and interaction, and associated high levels of service customization. In such settings, roles dominate the underlying service logic, and clearly defined and explicated roles determine the ultimate quality of the service experience - for both parties. In this case setting, diversional therapists are required to interact continuously with clients during service delivery and it is likely that this interaction requires them to customize service delivery in order to meet the unique therapeutic needs of respective clients. This omnipresent need to customize the service experience provides little opportunity for re-utilizing or scripting interactions and as a consequence, there is reduced opportunity to develop knowledge structures and event sequences that could be used as effective frames of reference for future service delivery. In 
terms of a dramaturgical perspective, the behavioral performance of diversional therapists is role bound, with scripts playing a minor role.

The model developed and tested in the current study attempts to describe the burnout impacts of role demands in a professional service setting, and is one of the few studies to model the consequences of concurrent socio-emotional and operational demand constructs on burnout symptoms. The model explains 55\% of the variance in emotional exhaustion and represents a significant advancement from earlier work, where models explain only $22 \%$ and $28 \%$ of the variance in emotional exhaustion (Stordeur et al., 2001 and Zapf et al., 2001, respectively). Importantly, the current model incorporates the ameliorating impact of emotional harmony on emotional exhaustion, which is thought to represent the replenishment of emotional resources deriving from successful service encounters.

\subsection{Managerial implications}

In light of the above, it is imperative that managers recognize the concurrent impact of the multiple forms of socio-emotional and operational demands made on employees in front line service settings, and the consequences that these demands have for employee well-being. Typically, the various operational demands are well understood in organizations and form an integral part of the job description and performance appraisal. Productivity targets are generally managed through task oriented negotiations. However, the multiple socioemotional demands are often less well understood and failure to recognize these can compromise both employee and organizational performance. The need for employees to display emotions that conform to the norms of service provision contributes to detrimental employee outcomes when these emotions are not genuine. However, this effect is substantially reduced when employees are allowed to express their positive emotions to 
customers/clients. Customer service managers who encourage a business-like and professionally distant emotional style may be inadvertently denying their service employees the opportunity to recoup their emotional resources and recue their emotional exhaustion. This increases the potential for employees to suffer from burnout and may have a consequential impact on service quality, both directly, as a result of depersonalization of customers, and indirectly, though an exhausted workforce suffering from stress related illness. Role overload and role ambiguity have, by far, the most deleterious impact on service workers' emotional exhaustion. This suggests that the idea of the universal worker, fulfilling a variety of service roles as and when needed, might be a self-destructive strategy for some service firms. The essential challenge for organizations involved in service delivery appears to be how to find ways of ensuring that service roles are properly defined and embedded in the design of the underlying service logic. Based on our study findings, there is strong evidence to suggest that this challenge is not being met, at least within the sample group.

In terms of future research, a number of opportunities present themselves. First, it would be of value to test the generalizability of this framework by subjecting it to replication in different service settings, including across a range of different service types. Second, it would be of value to examine the antecedent effect of flexible work arrangements, which are thought to characterize the work of such professionals and my reduce job-related stressors by allowing 'time out' for employees to recoup their emotional resources.

\subsection{Study Limitations}

The results of our study should be viewed in light of the study limitations. First, our sample is drawn from a professional association of allied health professionals. While representative of the members of the association, the sample does not represent all allied health professionals and results cannot necessarily be generalized to the sector, nor to the service sector as a whole. However, the results do offer some insights into the role of operational and socio- 
emotional demands made on employees. For our results to be fully generalizable a more comprehensive, multi industry study would be necessary.

Second, the size of our sample limits the statistical power of our analyses and the possibility of type I error, increasing the possibility that the significance of the relationships in our model is under represented. Some of the non-significant relationships in the model may actually be true relationships in the population.

Third, the causal relationships between the burnout dimensions remain a contested area of research. Taris et al. (2005) suggest that emotional exhaustion predicts depersonalization over time, and this depersonalization is associated with future exhaustion. Future studies examining the temporal relationships between the burnout dimensions may offer insights into their causal relationships with socio-emotional demands. It is plausible that displays of negative emotions result from emotional exhaustion, such that employees will contrive positive emotions and suppress negative emotions until their resources are depleted and they experience emotional exhaustion, at which point they are no longer able to suppress negative emotions and they become manifest. 


\section{Footnotes}

1. Following the request of a reviewer, we create a single score by summing the scores for role ambiguity, role conflict and role overload: the formative composite correlates at .39 with emotional exhaustion. Likewise, we also create a formative composite by adding up the scores for expressing contrived positive emotions, expressing genuine negative emotions, suppressing negative emotions, and subtracting from this total the score for expressing genuine positive emotions: the formed composite correlates at .45 with emotional exhaustion. It can be seen that, on average, the socio-emotional demands appear to have a slightly stronger relationship with emotional exhaustion than do the operational demands. However, an examination of the individual correlations that the facets of operational and socioemotional demand have with emotional exhaustion is perhaps most revealing - see Appendix 2. 


\section{References}

Anderson, J.C. and Gerbing, D.W. (1988), "Structural equation modelling in practice: A review and recommended two-step approach”, Psychological Bulletin, Vol. 103 No. 3, pp. 411-423.

Ashforth, B.E. and Humphrey, R.H. (1993), "Emotional labor in service roles: The influence of identity’, The Academy of Management Review, Vol. 18 No. 1, pp. 88-115.

Ashill, N.J. and Rod, M, (2011), "Burnout processes in non-clinical health service encounters”, Journal of Business Research, Vol. 64, pp. 116-127.

Atkinson, W. (2004), “Stress: Risk Management's Most Serious Challenge?”, Risk Management, Vol. 51 No. 6, pp. 20-24.

Bagozzi, R.P, Yi, Y. and Phillips, L.W. (1991), 'Assessing Construct Validity in Organizational Research’, Administrative Science Quarterly, Vol. 36 No. 3, pp. 421-458.

Barsade S.G., Brief A.P., Spataro S.E. (2003). "The affective revolution in organizational behavior: The emergence of a paradigm". In Greenberg J.. Organizational Behavior: The state of the science (2nd ed.). Hillsdale, NJ: Lawrence Erlbaum Associates. pp. 3-52.

Baumgartner, H. and Steenkamp, J-B.E.M. (2001), "Response Styles in Marketing Research: A Cross-National Investigation”, Journal of Marketing Research, Vol. 38 No. 2, pp. 143-156.

Bhanugopan, R. and Fish, A. (2006), “An empirical investigation of job burnout among expatriates”, Personnel Review, Vol. 35 No. 4, pp. 449-468.

Brotheridge, C. \& Lee, R. 2002. Testing a conservation of resources model of the dynamics of emotional labor. Journal of Occupational Health Psychology, Vol. 7 No.1. pp. 57 - 67.

Biddle, B.J. (1986), "Recent Developments in Role Theory”, Annual Review of Sociology, Vol.12, pp. 67-92.

Chen, G. Gully, S.M. and Eden, D. (2001), "Validation of a new general self-efficacy scale”, Organizational Research Methods, Vol. 4 No. 1, pp. 62 -83.

Chung, B.G, and Schneider, B. (2002), "Serving multiple masters: Role conflict experienced by service employees”, The Journal of Services Marketing, Vol. 16 No. 1, pp. 70-87.

Conley, S. and Woosley, S.A. (2000), "Teacher role stress, higher order needs and work outcomes”, Journal of Educational Administration, Vol. 38 No. 2, pp. 179-201.

Dorman, C., and Zapf, D. (2004), “Customer-Related Social Stressors and Burnout”, Journal of Occupational Health Psychology, Vol. 9 No. 2, pp. 61-82. 
Fogarty, T.J. Singh, J. Rhoads, G.K. and Moore, R.K. (2000), “Antecedents and consequences of burnout in accounting: Beyond the role stress model", Behavioral Research in Accounting, Vol. 12, pp. 31-67.

Fornell, C. and Larcker, D. (1981), "Structural equation models with unobservable variables and measurement error: Algebra and statistics”, Journal of Marketing Research, Vol. 18 No. 3, pp. 382-388.

Gerbing, D.W. and Anderson, J.C. (1988), “An updated paradigm for scale development incorporating unidimensionality and its assessment”, Journal of Marketing Research, Vol. 25 No. 2, pp. 186-186.

Golembiewski, R.T. and Munzenrider, R.F. (1989), "Burnout as an indicator of gamma II: state-like differences between phases", Journal of Health and Human Resources Administration, Vol. 12, pp. 245-260

Glomb T.M. and Tews, M.J. (2004), "Emotional labor: A conceptualization and scale development”, Journal of Vocational Behavior, Vol. 64, pp. 1-23.

Grandey, A. (2000). "Emotion Regulation in the Workplace: A New Way to Conceptualize Emotional Labor”. Journal of Occupational Health Psychology, Vol. 5, pp. 95-110.

Grandey, A. (2003). When "the Show Must Go On”: Surface and Deep Acting as Predictors of Emotional Exhaustion and Service Delivery”. Academy of Management Journal, Vol. 46, pp. 86-96.

Grandey, A.A. Fisk, G.M. and Steiner, D. D. (2005), "Must "Service with a Smile" Be Stressful? The Moderating Role of Personal Control for American and French Employees", Journal of Applied Psychology, Vol. 90 No. 5, pp. 893-904.

Hair, J.F. Anderson, R.E. Tatham, R.L. and Black, W.C. (1998), Multivariate Data Analysis (5 ed.). New Jersey: Pearson Education, Inc.

Hakanen, J.J. Perhoniemi, R. and Toppinen-Tanner, S. (2008), "Positive gain spirals at work: From job resources to work engagement, personal initiative and work-unit innovativeness", Journal of Vocational Behavior, Vol. 73 No. 1, pp. 78-91.

Halliday, S.V. Davies, B.J. Ward, P. and Lim, M. (2008), “A dramaturgical analysis of the service encounter in higher education”, Journal of Marketing Management, Vol. 24 No. 1/2, pp. 47-68.

Harman, H.H. (1967), Modern Factor Analysis. Chicago: University of Chicago Press

Hobfoll, S.E. (1989), “Conservation of Resources: A new attempt at conceptualizing stress”, American Psychologist, Vol. 44 No. 3, pp. 513-524.

Hobfoll, S.E. (1988), The Ecology of Stress. Washington, DC: Hemisphere. 
Hochschild, A.R. (1983), The Managed Heart: Commercialization of Human Feeling. Berkeley, CA: University of California Press.

Ivancevich, J.M. Matteson, M.T. and Preston, C. (1982), "Occupational stress, Type A behavior, and physical well being”, Academy of Management Journal, Vol. 25 No. 2, pp. 373-391.

Jeanquart Miles, S. and Mangold, G. (2004), “A conceptualization of the employee branding process”, Journal of Relationship Marketing, Vol. 3 No. 2/3, pp. 65-87.

Jenkins, S.R. and Maslach, C. (1994), "Psychological health and involvement in interpersonally demanding occupations”, Journal of Organizational Behavior, Vol. 15 No. 2, pp. 101-127.

Jöreskog, K. Sörbom, D. (2007), LISREL 8: Structural Equation Modeling with the SIMPLIS Command Language, Scientific Software International, Chicago, IL,

Judge, T.A. Woolf, E.F. and Hurst, C. (2009), "Is emotional labor more difficult for some than for others? a multilevel, experience-sampling study”, Personnel Psychology, Vol. 62 No. 1, pp. 57-88.

Kahn, R.L. Wolfe, D.M. Quinn, R.P. Snoek, J.D. and Rosenthal, R.A. (1964), Organizational Stress: Studies in Role Conflict and Ambiguity, New York: Wiley.

Kanste, O. Miettunen, J. and Kyngäs, H. (2006), "Factor structure of the Maslach Burnout Inventory among Finnish nursing staff”, Nursing and Health Sciences, Vol. 8, pp. 201-207.

Karatepe, O.M. and Uludag, O. (2008), "Role stress, burnout and their effects on frontline hotel employees' job performance: evidence from Northern Cyprus”, The International Journal of Tourism Research, Vol. 10 No. 2, pp. 111-126.

Kelloway, E.K. and Barling, J. (1990), “Item content vs. item wording: Disentangling role conflict and role ambiguity”, Journal of Applied Psychology, Vol. 75, pp. 738-742.

Kristensen, T.S. Borritz, M. Villadsen, E. and Christensen, K.B. (2005), "The Copenhagen Burnout Inventory: A new tool for the assessment of burnout”, Work and Stress, Vol. 19, pp. 192-207.

Lee, R.T. and Ashforth, B.E. (1996), "A meta-analytic examination of the correlates of the three dimensions of job burnout”, Journal of Applied Psychology, Vol. 81 No. 2, pp. 123-33.

Lee, R.T. and Ashforth, B.E. (1990), “On the meaning of Maslach's three dimensions of burnout”, Journal of Applied Psychology, Vol. 75, pp. 743-747.

Lee, J; Lim, N; Yang, E; Lee S.M. (2011), “Antecedents and Consequences of Three Dimensions of Burnout in Psychotherapists: A Meta-Analysis", Professional PsychologyResearch And Practice, Vol. 42 No. 3, pp. 252 - 258. 
Lee H., Song R., Young S.C., Lee G.Z., Daly B. (2003) “A Comprehensive Model for Predicting Burnout in Korean Nurses”, Journal of Advanced Nursing. Vol. 44 No. 5 pp. 534 45.

Leiter, M.P. (1993), “Burnout as a developmental process: consideration of models”, In:

(Eds.) Schaufeli W.B. Maslach, C. and Marek, T. Professional Burnout: Recent

Developments in Theory And Research, Washington: Taylor and Francis. pp. 19-32.

Leiter, M.P. and Maslach, C. (1988), "The impact of interpersonal environment on burnout and organizational commitment”, Journal of Organizational Behavior, Vol. 9, pp. 297-308.

Maslach, C. and Jackson, S.A. (1981), “The measurement of experienced burnout”, Journal of Occupational Behavior, Vol. 2 No. 2, pp. 99-114.

Maslach, C. and Leiter, M. P. (2008), "Early predictors of job burnout and engagement", Journal of Applied Psychology, Vol. 93, pp. 498-512.

Maslach, C. Jackson, S.E. and Leiter, M.P. (1996), MBI: The Maslach Burnout Inventory: Manual. Palo Alto: Consulting Psychologists Press.

Mattila, A.S. and Enz, C.A. (2002), “The role of emotions in service encounters”, Journal of Service Research, Vol. 4 No. 2, pp. 268-277.

Meyerson, D.E (1994). "Interpretations of stress in institutions: The cultural production of ambiguity and burnout”, Administrative Science Quarterly, Vol. 39 No. 4 pp. 628-653.

Ongori, H. and Agolla, J.E. (2008), “Occupational Stress in Organizations and Its Effects on Organizational Performance”, Journal of Management Research, Vol. 8 No. 3, pp. 123-135.

Peiro, J.M.; Gonzalez-Roma, V. Tordera, N. and Manas, M.A. (2001), "Does role stress predict burnout over time among health care professionals?”, Psychology and Health, Vol. 16 No. 5, pp. 511-525.

Peterson, M.F, Smith, P.B, Akande, A. Ayestaran, S, et al. (1995), "Role conflict, ambiguity, and overload: A 21-nation study”, Academy of Management Journal, Vol. 38 No. 2, pp. 429452.

Podsakoff, N.P., LePine, J.A., an LePine, M.A. (2007), "Differential Challenge StressorHindrance Stressor Relationships with Job Attitudes, Turnover Intentions, and Withdrawal Behavior: A Meta-analysis”. Journal of Applied Psychology, Vol. 92, pp. 438-454

Posig, M. and Kickul, J. (2003), "Extending our understanding of burnout: test of an integrated model in nonservice occupations", Journal of Occupational Health Psychology. Vol. 8 no. 1, pp. 3-19.

Rafaeli, A. \& Sutton, R. 1987. "Expression of emotion as part of the work role”, Academy of Management Review, Vol. 12, pp. 23 - 37. 
Rizzo, J.R. House, R.J. and Lirtzman, S.I. (1970), "Role conflict and ambiguity in complex organizations”, Administrative Science Quarterly, Vol. 15 No. 2, pp. 150-63.

Schaubroeck, J. Cotton, J.L. and Jennings, K.R (1989), “Antecedents and consequences of role stress: A covariance structure analysis”, Journal of Organizational Behavior. Vol. 2 No. 1, pp. 35-58.

Sethi, V. Barrier, T. and King, R.C. (1999), "An examination of the correlates of burnout in information system professionals”, Information Resources Management Journal, Vol. 12 No. 3, pp. 5-13.

Singh, J. Goolsby, J.R. and Rhoads, G.K. (1994), "Behavioural and psychological consequences of Boundary Spanning Burnout for Customer Service Representatives”, Journal of Marketing Research, Vol. 31, pp. 558-569.

Spector, P. E. and Jex, S. M. (1998), “Development of four self-report measures of job stressors and strain: Interpersonal Conflict at Work Scale, Organizational Constraints Scale, Quantitative Workload Inventory, and Physical Symptoms Inventory”, Journal of Occupational Health Psychology. Vol. 3 No. 4, pp. 356-367.

Spector, P. Chen, P.Y. and O’Connell, B.J. (2000), “A longitudinal study of relations between job stressors and job strains while controlling for prior negative affectivity and strains”, Journal of Applied Psychology, Vol. 85 No. 2, pp. 211-218.

Stordeur, S . D'hoore, W. \& Vandenberghe, C. (2001), "Leadership, organizational stress, and emotional exhaustion among hospital nursing staff”, Journal of Advanced Nursing Vol. 35 No. 4, pp. 533-542

Taris, T, le Blanc, P.M. Schaufeli, W.B. Schreurs, P.J.G. (2005), “Are there causal relationships between the dimensions of the Maslach Burnout Inventory? A review and two longitudinal tests”, Work and Stress, Vol. 19, pp. 238-255.

Toppinen-Tanner, S. (2011), Process of burnout: structure, antecedents, and consequences. People and Work Research Reports 93, Finnish Institute of Occupational Health, Helsinki, Finland.

Tourigny, L. Baba, V.V. and Wang, X. (2010), 'Burnout and depression among nurses in Japan and China: The moderating effects of job satisfaction and absence”, The International Journal of Human Resource Management, Vol. 21 No. 15, pp. 2741-2761.

Tremblay P.F. \& Gardner R C, ((1996), "On the growth of structural equation modeling in psychological journals”, Structural Equation Modeling: A Multidisciplinary Journal, Vol. 3 No. 2, pp. 93-104.

Van Dierendonck, D. Schaufeli, W.B. and Buunk, B.P. (2001), "Toward a process model of burnout: Results from a secondary analysis”, European Journal of Work and Organizational Psychology, Vol. 10, pp. 41-52. 
Vargo, S.L. and Lusch, R.F. (2008), "Service-dominant logic: continuing the evolution", Journal of the Academy of Marketing Science, Vol. 36 no. 1, pp. 1-10.

Vargo, S.L. and Lusch, R.F. (2005), “Consumers' Evaluative Reference Scales and Social Judgment Theory: A Review and Exploratory Study', in Malhotra N.K. (ed.) Review of Marketing Research (Volume 1), 245-284.

Wu, S., Zhu, W., Wang Z., Wang M., Lan Y. (2007) "Relationship Between Burnout and Occupational Stress Among Nurses in China”. Jounal of Advanced Nursing, Vol.59 No. 3, pp. 233-9.

Zapf, D. Seifert, C. Schmutte, B. Mertini, H. \& Holz, M, (2001), "Emotion work and job stressors and their effects on burnout”, Psychology \& Health, Vol. 16 No. 5, pp. 527-545. 


\section{Appendix 1 (measures)}

\section{Emotional Exhaustion}

MBIEE1 At the end of my work day I feel emotionally drained

MBIEE2At the end of my work day I feel used up

MBIEE5 At the end of my work day I feel burned out

\section{Personal Accomplishment}

MBIPA2 At work I deal with problems effectively

MBIPA8 At work I deal with problems calmly

\section{Depersonalization}

MBID1 At work I sometimes treat patients as impersonal objects

MBID2 Through my work I have become callous

\section{Expressing positive emotions you feel}

How often do you genuinely express when you do feel that way?

ELF9 Happiness

ELF11 Liking

ELF14 Enthusiasm

\section{Expressing negative emotions you feel}

How often do you genuinely express when you do feel that way?

ELF1 Irritation

ELF6 Disliking

ELF7 Aggravation

ELF8 Fear

ELF10 Distress

\section{Expressing contrived emotions}

How often do you express feelings of on the job when you really DO NOT feel that way?

ELNF9 Happiness

ELNF11 Liking

ELNF14 Enthusiasm

\section{Suppressing negative emotions}

How often do keep feelings of ELS6 Disliking

ELS7 Aggravation

ELS8 Fear

ELS12 Hate

ELS13 Anger

\section{Role Ambiguity}

RA1 I know exactly what is expected of me at work (r).

RA2 I know what my responsibilities at work are (r).

RA5 I am clear about how much authority I have (r). 


\section{Role Conflict}

RC2 I sometimes have to break or bend the rules to do my job.

RC4 I do things that are accepted by one person and not accepted by others.

\section{Role Overload}

RO1 There is a need to reduce some parts of my role

RO2 I feel overburdened in my role

RO3 I have been given too much responsibility, my workload is too heavy

RO4 The amount of work I have to do interferes with the quality I want to maintain 
Appendix 2 Correlations and tests for discriminant validity*

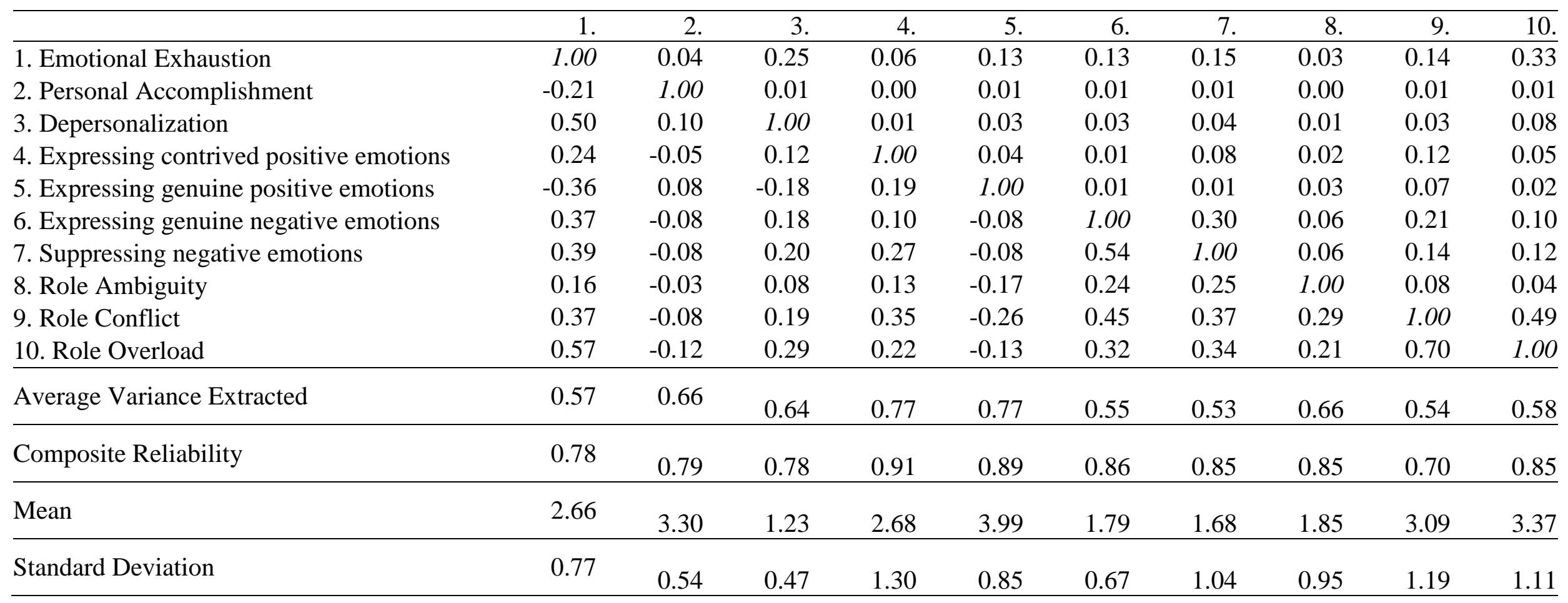

*Values below the diagonal are correlations: values above the diagonal are squared correlations. 